\title{
An Innovative Network to Improve Sea Ice Prediction in a Changing Arctic
}

\author{
Cecilia M. Bitz \\ Atmospheric Sciences MS351640 \\ University of Washington \\ Seattle, WA 98196-1640 \\ phone: (206) 543-1339 fax:(206) 543-0308 email: bitz@uw.edu
}

Award Number: N00014-13-1-0793

http://www.arcus.org/sipn

\section{LONG-TERM GOALS}

The overarching goal of this project is to understand sea ice predictability and improve sea ice predictions system by defining key observations, improve technical approaches for prediction, and refine communication of predictions.

\section{OBJECTIVES}

To achieve our goals, our project will establish a collaborative network of scientists and stakeholders known as the Sea Ice Prediction Network (SIPN). The SIPN leadership team extends beyond the University of Washington component, and the team receives multi-agency sponsorship. The University of Washington team, funded by ONR, is focused on the following three objectives:

(1) Coordinate and evaluate predictions: The SIPN team organizes the Sea Ice Outlook (SIO) each summer. A core group of dynamical and statistical modelers in SIPN is exploring the limits of Arctic sea ice predictability over seasonal-to-interannual time scales. We lead the design of SIO and additional experiments to intercompare predictions with common methods. We will also develop strategies for predictability studies that isolate the role of uncertainty in initial conditions and inherent model predictability and develop skill metrics tailored to evaluate sea ice predictions. At the same time, we will work with our SIPN collaborators to identify and evaluate the types of data that bring about measurable improvements in model performance and predictive skill and serve as the initial conditions for predictions. This effort will provide guidance on observing system needs and a synthesis of predictive skill assessments from different approaches for highpriority variables. A final objective of our group is to identify model deficiencies and work with model developers to improve models for prediction.

(2) Synthesize predictions and observations: We will review summer monthly sea ice evolution, open water sea surface temperature (SST) fields, and atmospheric forcing (wind and radiation) to synthesize findings and include modeling to place recent sea ice change into system-wide context. We will use models and observations to ask whether "2007-2012 is the New Normal" or "was natural variability responsible in part for rapid loss from 2007-2012, and moderated loss is more probable now". Through comparisons of the observed sea ice evolution and relevant processes with previous SIO predictions, the strengths and weaknesses of different prediction approaches 


\section{Report Documentation Page}

Form Approved

OMB No. 0704-0188

Public reporting burden for the collection of information is estimated to average 1 hour per response, including the time for reviewing instructions, searching existing data sources, gathering and maintaining the data needed, and completing and reviewing the collection of information. Send comments regarding this burden estimate or any other aspect of this collection of information,

including suggestions for reducing this burden, to Washington Headquarters Services, Directorate for Information Operations and Reports, 1215 Jefferson Davis Highway, Suite 1204, Arlington

VA 22202-4302. Respondents should be aware that notwithstanding any other provision of law, no person shall be subject to a penalty for failing to comply with a collection of information if it

does not display a currently valid OMB control number.

1. REPORT DATE

30 SEP 2014

4. TITLE AND SUBTITLE

An Innovative Network to Improve Sea Ice Prediction in a Changing Arctic

6. $\operatorname{AUTHOR}(\mathrm{S})$

7. PERFORMING ORGANIZATION NAME(S) AND ADDRESS(ES)

University of Washington,Atmospheric Sciences

MS351640,Seattle,WA,98196

9. SPONSORING/MONITORING AGENCY NAME(S) AND ADDRESS(ES)

3. DATES COVERED

00-00-2014 to 00-00-2014

5a. CONTRACT NUMBER

5b. GRANT NUMBER

5c. PROGRAM ELEMENT NUMBER

5d. PROJECT NUMBER

5e. TASK NUMBER

5f. WORK UNIT NUMBER

8. PERFORMING ORGANIZATION

REPORT NUMBER

10. SPONSOR/MONITOR'S ACRONYM(S)

11. SPONSOR/MONITOR'S REPORT

NUMBER(S)

12. DISTRIBUTION/AVAILABILITY STATEMENT

Approved for public release; distribution unlimited

13. SUPPLEMENTARY NOTES

14. ABSTRACT

15. SUBJECT TERMS

16. SECURITY CLASSIFICATION OF:

a. REPORT

unclassified b. ABSTRACT

unclassified c. THIS PAGE

unclassified
17. LIMITATION OF ABSTRACT

Same as

Report (SAR)
18. NUMBER 19a. NAME OF

OF PAGES RESPONSIBLE PERSON

10 
will be evaluated. At the same time we will explore how methods can be combined to improve understanding and forecasts.

(3) Disseminate predictions: We are improving the content, format and delivery of products from the SIO to address information and research needs of key stakeholders (including federal and state agencies) and build a more informed public. We are requesting that SIO contributors provide more specific regional forecasts, more accessible meta-analysis, and information to compare research approaches.

\section{APPROACH}

We undertook a concerted effort this year to reach out to the community of scientists and stakeholders interested in sea ice prediction by creating and maintaining the SIPN website, creating mechanisms for interested parties to join the SIPN email list and sign up for action teams, and holding a meeting at AGU in Dec. 2013 and a webinar in Feb. 2013 to disseminate the network plans and invite particiants. We organized and hosted a workshop in Apr. 2014 to share ideas and create new goals and design new procedures for the SIO.

Key individuals supported by ONR at University of Washington include Cecilia Bitz (project PI is in charge of management and action teams to coordinate and evaluate modeling efforts to predict sea ice), Edward Blanchard-Wrigglesworth (postdoc assists with organizing modeling activities, including intercomparison experiments and designing and analyzing new metrics for the SIO outlook), James Overland (at no cost, is in charge of synthesizing predictions and observations to assess the state of the Arctic sea ice), and Muyin Wang (research scientist is organizing a SIPN modeling experiment with initial conditions used by all modeling centers, assists with synthesis and analysis).

Key members of the larger team of collaborators forming the SIPN leadership team and supported by other agencies are Hajo Eicken (UAF, observationalist, interfacing with other national and international groups), Julienne Stroeve (CU, observational data acquisition and dissemination), Phil Jones and Elizabeth Hunke (LANL, model improvements), Lawrence Hamilton (UNH, interfacing with stakeholders), Walt Meier (NASA, satellite observations), and Helen Wiggins and Betsy TurnerBogran (ARCUS, communications and network function).

Cecilia Bitz and James Overland joined the IARPC sea ice team to further facilitate communication about SIPN and sea ice prediction. Cecilia reported on the SIPN workshop in May 2014. In May 2014, Muyin Wang, James Overland, and Edward Blanchard-Wrigglesworth attended the NOAA Science Challenge Worshop "Predicting Arctic Weather and Climate and Related Impacts" held at NOAA/ESRL in Boulder, CO. During the workshop our team actively participated in the discussions, and contributed to the draft report which later being submitted by the organizing committee to the higher level of NOAA.

Muyin contacted modeling groups in China (IAP, BCC, FIO, and Tsinghua University) in early June to invite their participation in the SIO activities. The reaction from the teams are positive, however due to time constraint, none of them were able to submit their results this year.

Our UW team joins SIPN leadership team webinars approximately once per month. The leadership team together plans each SIO call for contributions, with the intention of enhancing the scientific 
content of the SIO, by developing a questionare template. The UW team has been especially involved in requesting details on the questionare about modeling methods, requesting hindcast skill, and requesting two new local-scale fields: (1) probabilistic forecast of sea ice extent (SIE), referred to as "sea ice probability", or SIP, and (2) first "ice-free date", or IFD, as a Julian day when sea ice concentration falls below $15 \%$. The data for SIP and IFD have been sent directly to UW team member Ed Blanchard-Wrigglesworth for analysis. We contribute to the analysis of SIO contributions and observations to prepare the nowcast and synthesis of for the SIO reports that are published each month from June to August, and we are presently collaborating with a SIPN action team to write the annual SIO report and a journal article summarizing the results.

In addition to organizing the SIO activities, the UW team is running a the Community Earth System Model version 1 (CESM1) to contribute our own outlook to the SIO and to conduct experiments on sea ice predictability. We are analyzing SIO contributions, observations to prepare a nowcast for the SIO, and CESM1 and other CMIP5 model output to investigate questions about natural variability and forced sea ice change. Finally, we are evaluating CFSv2 forecasts to better understand the characteristics of the forecast system's atmosphere.

\section{WORK COMPLETED}

The UW team contributed to the preparation of the three calls for SIO contributions, analyzing the SIO contributions, and writing the SIO summary reports in June, July, and August 2014. The SIO summaries contain a nowcast of sea ice conditions and our analysis of the SIO contributions. These reports are published on the SIPN web site.

Cecilia Bitz and Ed Blanchard-Wrigglesworth collaborated with other SIPN leadership team members Julienne Strove and Lawrence Hamilton to analyze the skill of SIO 2008-2013 contributions. The UW participants contributed expertise on modeling and predictability. We wrote a journal article together that was published (Stroeve et al, 2014, see publications list).

Cecilia Bitz and Julienne Strove wrote a newsletter for CLIVAR titled "Sea Ice Predictability", which describes SIPN, SIO, and reviews the topic of sea ice predictability (Bitz and Stroeve, 2014, see publications list).

In our February 2014 webinar and through our email list, we invited SIPN participants to contribute to a model intercomparison experiment. The experiment was intentionally made simple so contributions could be submitted before the workshop. The goal of the experiment was to test the response of different models to identical anomalies in their initial conditions to address the large spread across the model outlooks in the SIO 2008-2013. The project consisted of initializing forecasts with identical thickness perturbations: a decrease in initial sea ice thickness of 1 meter throughout the Arctic. Ed Blanchard-Wrigglesworth analyzed the results and presented them in a session he organized at the SIPN 2014 workshop. The workshop session included presentations by four early career scientists on the more pressing problems in Arctic predictability.

Ed Blanchard-Wrigglesworth co-authored a peer-reviewed paper that is a comprehensive review of sea ice predictability (Guemas et al, 2014, see publications list). He also finished his own first-author paper (Blanchard-wrigglesworth and Bitz, 2014, see publication list) that characterizes sea ice thickness variability from a predictability perspective. 
Ed Blanchard-Wrigglesworth performed a series of sensitivity experiment in which the sensitivity of sea ice predictability to different boundary conditions was examined in a model. Results from his previous work has showcased that sea ice predictability is conditioned by the climate's mean state of a model. For example, sea ice that is thicker is thought to be predictable for a longer time period than thinner sea ice. In our experiments, we investigated how changes in snow cover affect predictability in the CESM1. Snow cover may be particularly relevant to summer sea ice predictability, as it affects surface radiative fluxes and the timing of ice melt onset during early summer.

Muyin Wang downloaded the NCEP CFSv2 operational seasonal forecast twice a month since Feb. 2014.

Cecilia Bitz worked with colleagues in Norway and Belgium to examine the role of natural variability in contributing to the high rate of Arctic sea ice loss in the last decade. We address the question of how the rate of loss in the future is overestimated by extrapolating the trend from a decade with loss that is strongly enhanced by natural variability. This work resulted in a submitted article (Hezel et al., submitted, see publication list).

\section{RESULTS}

We requested two new fields this year in July and August from SIO participants. We received these new fields from 4 of the 23 SIO participants, and many more indicated they would be able to submit these fields in subsequent years. Figure 1 illustrates one of the new fields, known as Ice-Free Day (IFD) in a pair of outlooks, with validation we produced from observations (for IFD through August 2014). The IFD maps parallel the Sea Ice extent Probability (SIP) maps (not shown), with regions of low or zero sea ice extent probabilities having early melt dates. Regions near the Mackenzie Delta and the Laptev Sea are earliest to melt out in the outlooks, while the East Siberian Sea has late IFD compared to other coastal regions. The observed IFD for 2014 also has early dates in the Laptevs Sea (compared to the 2003-2012 climatology) and the East Siberian Sea has late IFD on average. We are encouraged by our first view of these new fields, and expect even better results from intercomparing across models when more groups can provide these fields in the future.

The contributions of pan-Arctic SIE outlooks to the SIO from 2008-2013 were examined and results were published in a study by Stroeve et al. (2014), which shows that the median prediction of the contributions tended to be accurate in years when the SIE is near its long-term trend. In years when the observed SIE departs from the trend, the median and most individual predictions are less accurate. This study initiated more advanced analysis of the SIO than had been presented in the SIO reports, and the method of presenting outlooks in a box-and-whisker plot broken down by the type of contribution was carred over to the SIO reports in 2014. Figure 2 shows an example from the August 2014 SIO report, where quantitative methods can be seen to have less spread than the heuristic methods, and the middle of the distributions in all but the mixed method predicted a higher SIE over the course of the summer. This year the September SIE is likely to be very near the 2013 level (grey line in Fig. 2), and hence the forecast error improved with shorter lead times, as one would hope. However, we found the outlooks from 2008-2013 did not on average exhibit this improvement in forecast at shorter lead times. 

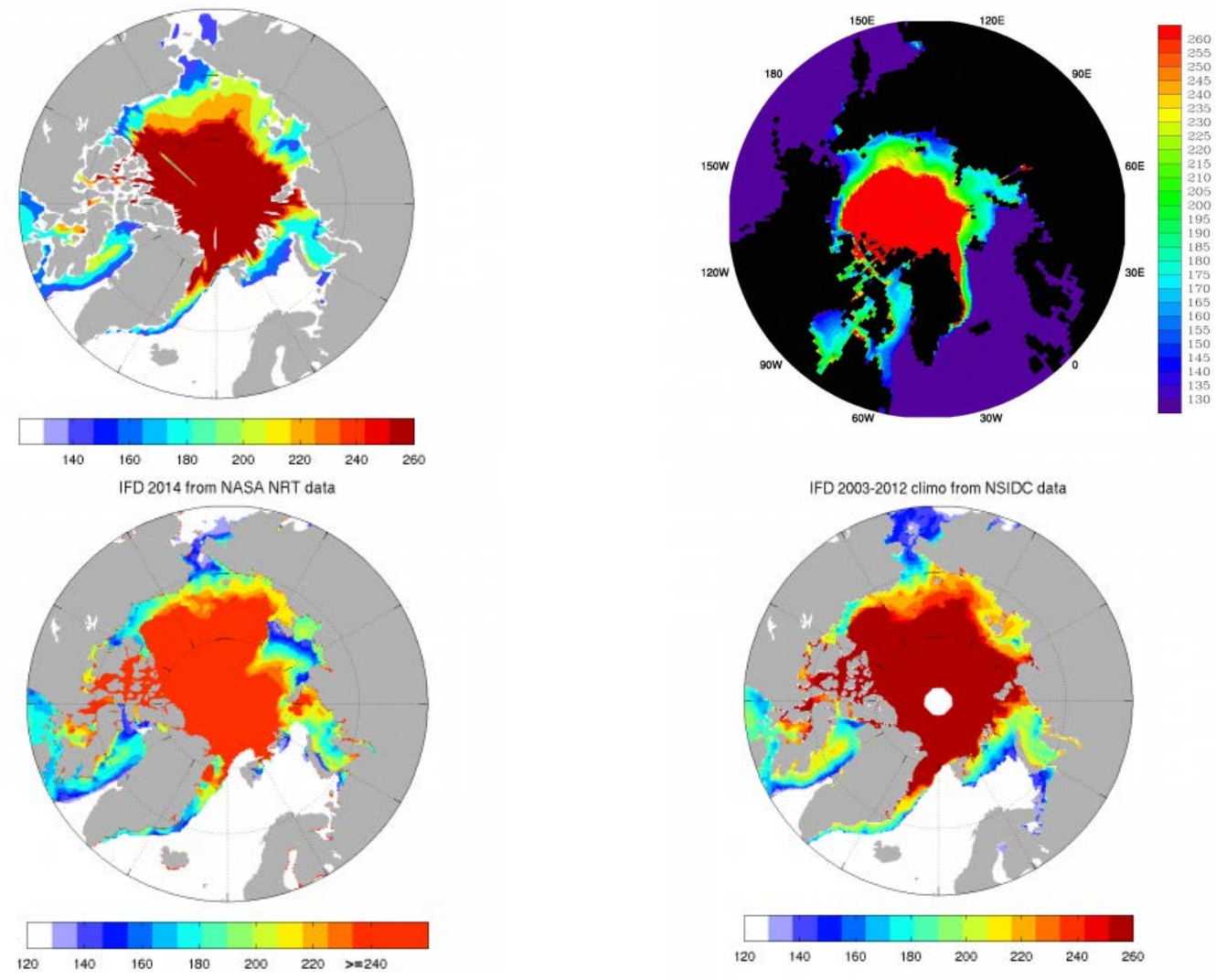

Figure 1: Estimates of first Ice-free Day (IFD) in 2014 for two of the outlooks submitted in August 2014 (top row) and from passive microwave sea ice observations for 2014 by the end of August (bottom row, left) and in the climatological mean of 2003-2012 (bottom row, right). The bottom left panel is limited to dates before the end of August. 


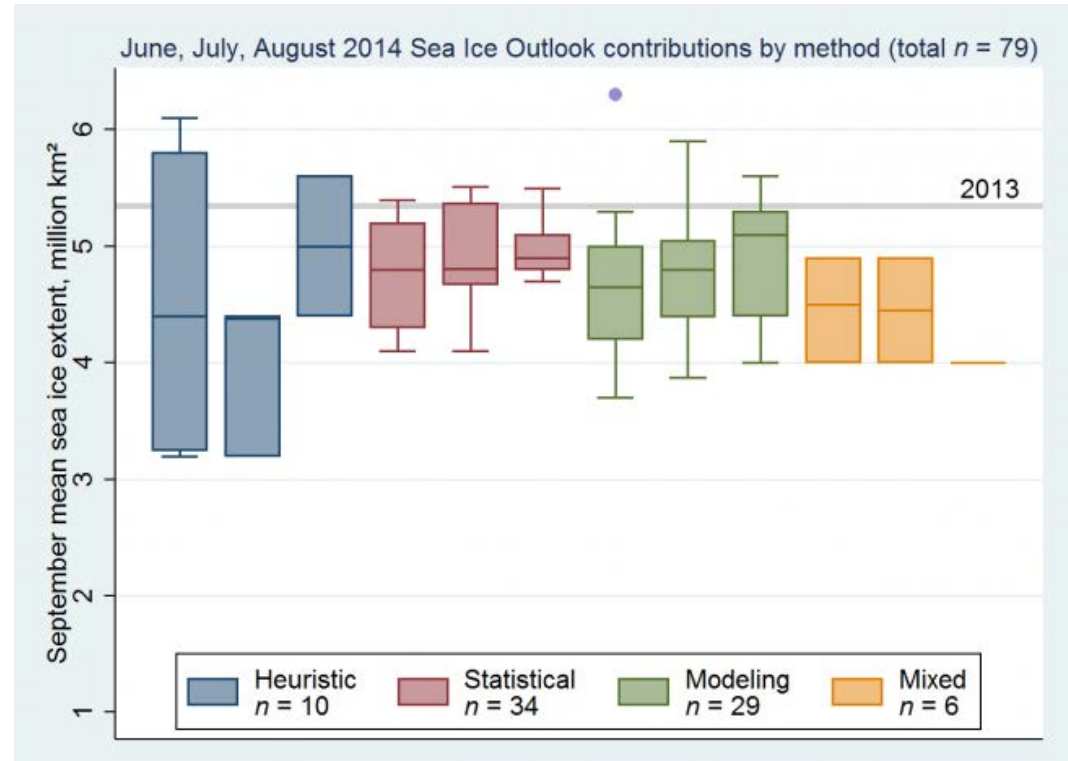

Figure 2: June, July, and August 2014 predictions of September pan-Arctic sea ice extent (million $\mathrm{km}^{2}$ ). Boxes show the inner quartile range of the distribution for each set of prediction methods, grouped by type. The observed September 2013 extent of 5.3 million $\mathrm{km}^{2}$ is indicated by the grey line, and the September 2014 is likely to be roughly the same. The dot near the top of the figure indicates a statistical outlier.

In our February webinar, we invited SIPN participants to contribute to a forecast intercomparison of how sensitive the 2013 September forecast using May initial conditions is to a $1 \mathrm{~m}$ perturbation in the initial conditions. (We suggested alternatives to groups that use variables other than thickness in their forecasts initialization, but none contributed.) The four modeling groups that contributed had widely varying sensitivity in their September SIE forecast, between -2 and -4 million square kilometers per 1 $\mathrm{m}$ thickness perturbation (See Fig. 3). This result suggests that different model physics play a significant role in the overall spread seen in SIO, and that even if all models were to utilize identical initial conditions, a significant spread in September outlooks would remain.

We performed additional experiments in the CESM1, the model we use for our group's outlooks. We found that reducing late spring/summer snow cover results in reduced predictability of summer SIE, particularly during July/August. The loss of predictability results from a lower surface albedo occurring earlier in summer. Our previous work has shown that there is a 'predictability barrier' in early summer (Blanchard-Wrigglesworth et al., 2011a) - a time during which predictability is lost at a faster pace than other times of the year. In essence, a decrease in spring snow depth in the Arctic results in an earlier predictability barrier, thus leading reduced summer sea ice predictability. This suggests that models with a bias in snow cover relative to observations may have a biased summer sea ice predictability, and that a decrease in snow depth in a future global warming scenario may result in reduced predictability. 


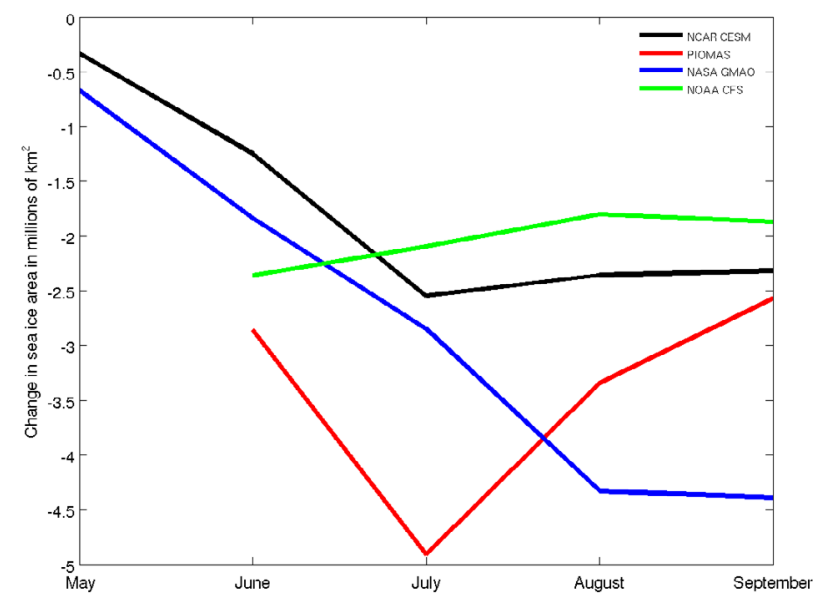

Figure 3. Response of pan-Arctic sea ice area forecasts in four models to a 1-m perturbation in the initial sea ice thickness. All models have less sea ice, but by an amount that varies widely.
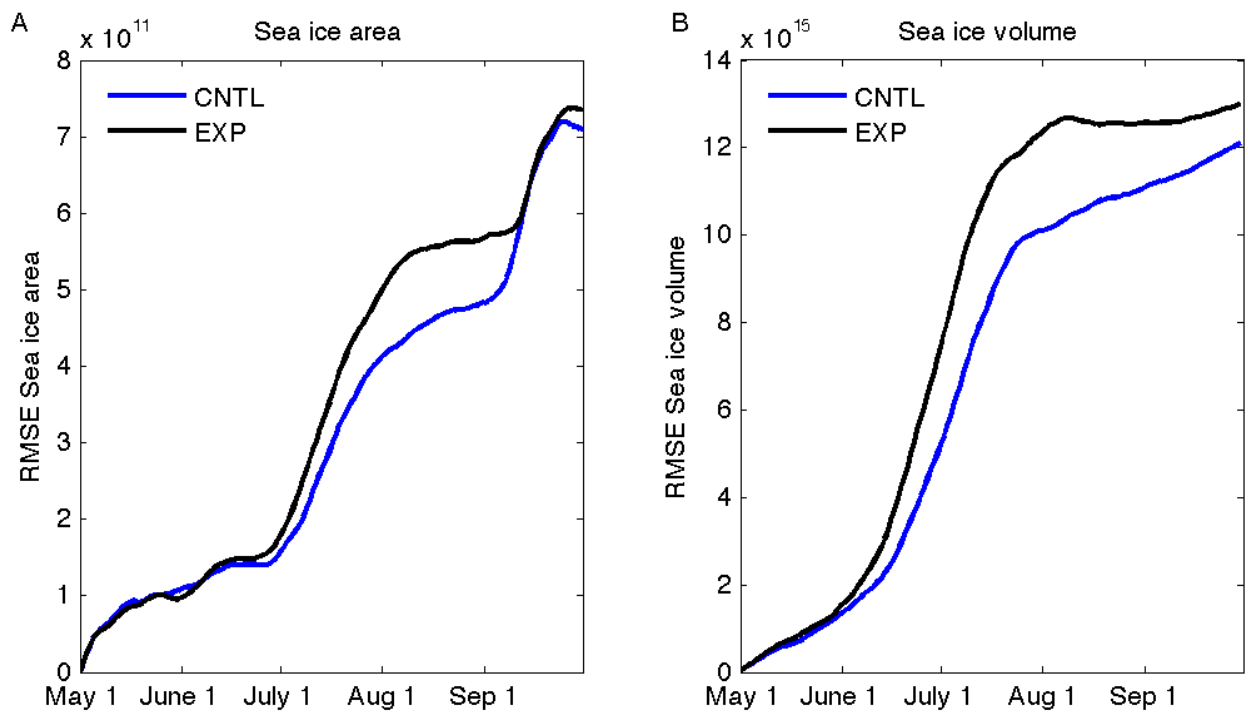

Figure 4: Root Mean Square Error (RMSE) in CESM1 simulations with unperturbed May 1 snow on sea ice (CNTL) and perturbed May 1 snow on sea ice (EXP) for (A) sea ice area and (B) sea ice volume. The EXP ensemble is initialized with 1/5 of CNTL snow depths, thus resulting in a reduced snow cover and lower summer albedo. The predictability barrier (rapid rise in RMSE) takes place about a week earlier in the EXP and is also larger in magnitude.

In 2014 we completed a study that culminated in a paper in press (Blanchard-Wriggleworth and Bitz) that examines variability of sea ice thickness in different models (both fully coupled GCMs and iceocean only models forced with an observed atmosphere). Sea ice thickness is considered to be a key predictor for sea ice forecasts, yet its intrinsic variability has received little attention. We showed that there is a significant spread across models in key features that characterize ice thickness variability: its amplitude, length and temporal scales show a two-to-three fold spread across models. These models are being used for sea ice predictability with enhanced frequency, and our results indicate that models 
with large biases in thickness with respect to observations may be inadequate tools for sea ice prediction.
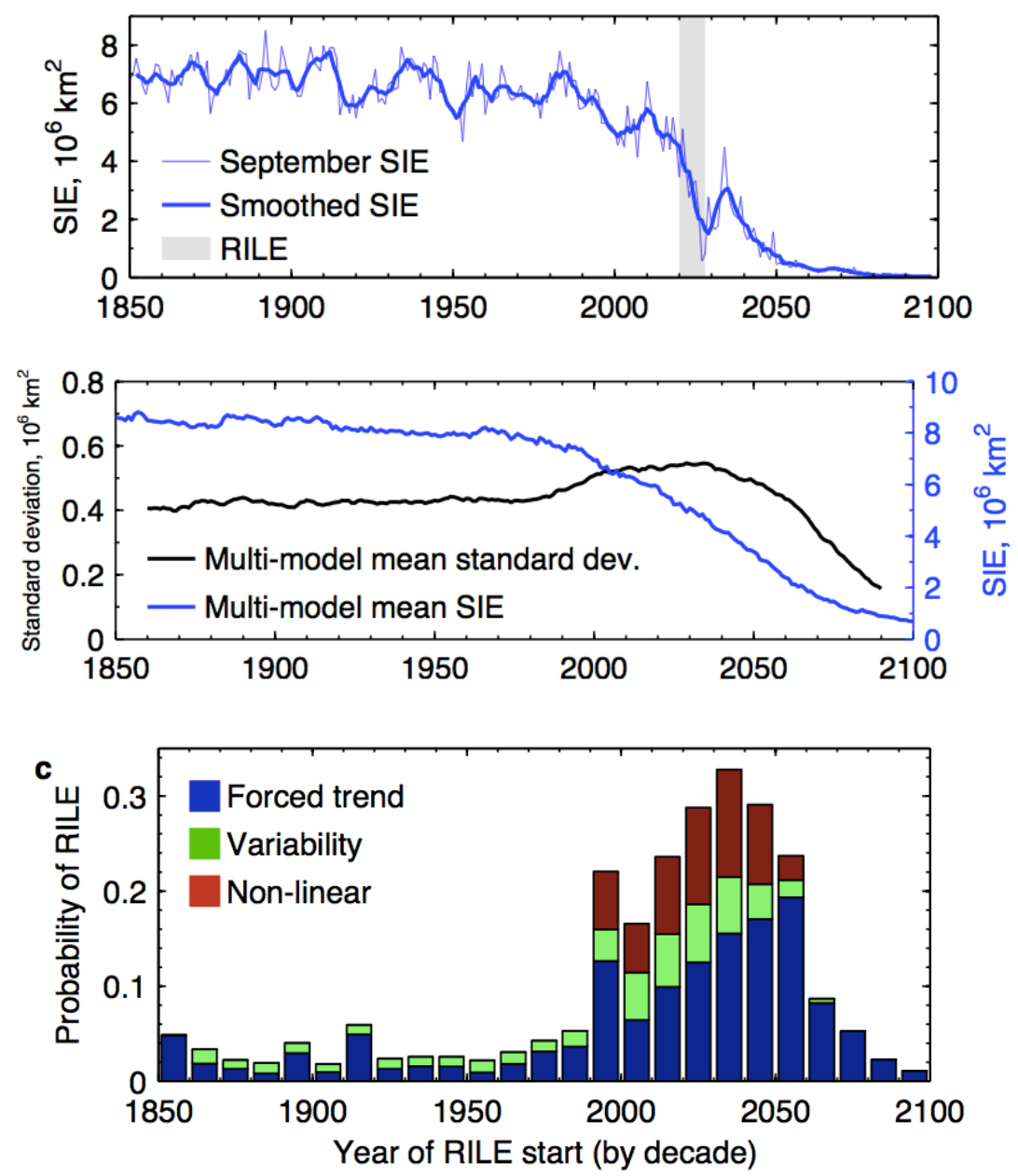

Figure 5: Example of a time series of September Arctic SIE with a Rapid Ice Loss Event (RILE) in the ACCESS 1.0 model (top). The increasingly downward trend in SIE in the CMIP5 multi-model mean and the increasing variability as indicated by the cross-ensemble standard deviation of SIE (middle) are contributors to the increase in probability of RILES after 1990 (bottom).

We investigate the consequences of identifying the recent observed SIE loss as a rapid ice loss event (RILE) and submitted the results (Hezel et al.). The improved agreement in the more recent CMIP5 models with the observed decline over the satellite era (e.g., Stoeve et al, 2012) and the large number of available ensemble members present the opportunity to estimate the probability of RILE occurrence this century (see Fig. 5). We found that RILEs, defined as rare events in the historical simulations, are quite common in the first half of this century, with probabilities of occurrence in each decade from 20 $40 \%$. We then use the evolution of the September SIE after each RILE in the CMIP5 simulations to show that the rapid sea ice decline observed in the Arctic is unlikely to accelerate or even continue in the coming decades. Our results are consistent with the observed SIE in 2013 and 2014. 


\section{IMPACT/APPLICATIONS}

Loss of sea ice in recent decades has opened the Arctic Ocean to increasing access of wide-ranging vessels and activities. The Navy is concerned about the potential for conflict and need for search and rescue on the Arctic Ocean. Each year the sea ice cover is different owing to natural variability and forced change. Forecasts of Arctic sea ice and atmospheric conditions have high societal value if they predict when ship transit lanes will be open and where low ice cover might lead to dangerous coastal erosion or ice shelf break-up. Sea ice forecasts have scientific value as they could inform scientists of locations that should be instrumented to monitor large anomalies. This project aims to improve Arctic sea ice prediction of the natural variability and forced change, which is a benefit to society, scientists, and Naval operations. We also seek to improve sea ice models in general.

\section{RELATED PROJECTS}

ONR project N00014-13-0792 Early Student Support to Investigate the Role of Sea Ice-Albedo

Feedback in Sea Ice Predictions is also about understanding sea ice predictability.

\section{REFERENCES}

Blanchard-Wrigglesworth, E., K. Armour, C. M. Bitz, and E. deWeaver, 2011a: Persistence and inherent predictability of Arctic sea ice in a GCM ensemble and observations. J. Climate, 24, 231250, doi:10.1175/2010JCLI3775.1.

Blanchard-Wrigglesworth, E., and C.M. Bitz, 2014: Characteristics of Arctic Sea-Ice Thickness Variability in GCMs. J. Climate. In press, doi:10.1175/JCLI-D-14-00345.1.

Hezel, P.J., C.M. Bitz, T. Fichefet, H. Goosse, and F. Massonnet, 2014: Recent and future Arctic sea ice decline from the perspective of a Rapid Ice Loss Event, submitted.

Stroeve, J., Kattsov, V., Barrett, A. P., Serreze, M., Pavlova, T., Holland, M., and Meier, W., 2012: Trends in arctic sea ice extent from CMIP5, CMIP3 and observations, Geophys. Res. Lett., 39, L16502, doi:10.1029/2012GL052676.

Stroeve, J., L. C. Hamilton, C. M. Bitz, and E. Blanchard-Wrigglesworth, 2014: Predicting September sea ice: Ensemble skill of the SEARCH Sea Ice Outlook. Geophys. Res. Lett., 41, 2411-2418, doi:10.1002/2014GL059388.

\section{PUBLICATIONS}

Blanchard-Wrigglesworth, E., and C.M. Bitz, 2014: Characteristics of Arctic Sea-Ice Thickness Variability in GCMs. J. Climate. doi:10.1175/JCLI-D-14-00345.1, [in press, refereed].

Bitz, C.M. and J. Stroeve, 2014: “Sea Ice Predictability”, CLIVAR Variations Newsletter, Eds. Judah Cohen and Kristan Uhlenbrock, Sumer Edition, [published]. 
Stroeve, J., L.C. Hamilton, C.M. Bitz, E. Blanchard-Wrigglesworth, 2014: Predicting September sea ice: Ensemble skill of the SEARCH Sea Ice Outlook 2008-2013, Geophys. Res. Lett., 41, 24112418 doi: 10.1002/2014GL059388, [published, refereed].

Guemas, V. E. Blanchard-Wrigglesworth, M. Chevallier, J. J. Day, M. Deque, F. J. Doblas-Reyes, N. Fuckar, A. Germe, E. Hawkins, S. Keeley, T. Koenigk, D. Salas y Melia, and S. Tietschel, 2014: A review on Arctic sea ice predictability and prediction on seasonal-to-decadal timescales. Quart. J. Roy. Met. Soc, doi:10.1002/qj.2401, [in press, refereed].

Hezel, P.J., C.M. Bitz, T. Fichefet, H. Goosse, and F. Massonnet, 2014: Recent and future Arctic sea ice decline from the perspective of a Rapid Ice Loss Event, [submitted, refereed]

Overland, J. E., J. Wang, R. S. Pickart, and M. Wang (2014), Recent and Future Change in the Meteorology of the Pacific Arctic, in The Pacific Arctic Region: Ecosystem Status and Trends in a Rapidly Changing Environment, edited by J. M. Grebmeier and W. Maslowski, p. 535, Springer. [published, refereed]

Overland, J. E., M. Wang, J. E. Walsh, and J. C. Stroeve (2014), Future Arctic climate changes: Adaptation and mitigation time scales, Earth's Future, 2(2), 68-74, doi:10.1002/2013EF000162. [published, refereed]

Post, E, U. Bhatt, C. M. Bitz, J. Brodie, T.L. Fulton, M. Hebblewhite, J. Kerby, S. Kutz, I. Stirling, and D.A. Walker, 2013: Sea ice as driver of ecological responses to climate change in the Polar Regions, Science, 341, DOI: 10.1126/science.1235225, [published, refereed].

\section{HONORS/AWARDS/PRIZES}

James Overland of NOAA PMEL has won a 2014 Ambassador Award from the American Geophysical Union.

Cecilia Bitz of University of Washington was a Fulbright Fellow at University of Otago, New Zealand from Nov. 2014-Feb. 2015.

Cecilia Bitz of University of Washington was the Sears lecturer of the 2014 Geophysical Fluid Dynamics Summer School at the Woods Hole Institute.

Cecilia Bitz of University of Washington in 2014 was elected a fellow of the American Meteorological Society. 